\title{
Efficacy and safety of Vinflunine for advanced or metastatic urothelial carcinoma in routine practice based on the French multi-centre CURVE study
}

\author{
Jacques Médioni ${ }^{1 *}$, Mario Di Palma², Aline Guillot ${ }^{3}$, Dominique Spaeth ${ }^{4}$ and Christine Théodore ${ }^{5}$
}

\begin{abstract}
Background: To retrospectively assess the efficacy and safety of Vinflunine (VFL) under routine conditions and identify overall survival (OS) prognostic factors.

Methods: Twenty centres participated in the retrospective study (minimum 4 patients undergoing VFL treatment for advanced/metastatic UC after platinum-based regimen progression. Primary endpoint was OS. Secondary endpoints: progression-free survival (PFS), radiological response rate (RR) RECIST criteria and toxicity (CTC NCI v3).

Results: These centres enrolled 134 patients. Prior chemotherapy (CT) lines ( $\geq 1$ palliative): 1 and $\geq 2$ in $69 \%$ and $26 \%$ of patients, respectively. Performance status (PS): 0, 1, 2 in $25 \%, 46 \%$ and $23 \%$ of patients. Median OS $=8.2$ months [6.5-9.4], PFS $=4.2$ months and RR $22 \%$, median number of 5 cycles. In risk groups based on 0-3 presence of adverse prognostic factors (PS $\geq 1$, haemoglobin $\leq 10 \mathrm{~g} / \mathrm{dl}$ and liver metastasis), median OS: 13.2, 9.9, 3.6, and 2.4 months $(P<.0001)$, respectively; 3.3 months $(1.9-5.6)$ in $P S \geq 2$ subgroup.

Conclusion: This study reflects routine UC management and confirmed VFL patient efficacy. The drug is safe with gastro-intestinal and haematological prophylaxis. Analysis of prognostic factors for OS is consistent with pivotal trials.
\end{abstract}

Keywords: Vinflunine, Metastatic, Urothelial carcinoma, Chemotherapy, Routine, Platinum pre-treated, CURVE (urothelial carcinoma patients treated by VinfluninE study-in French)

\section{Background}

Bladder cancer is a major health problem with an estimated 429,793 new cases and 165,068 related deaths in 2012, worldwide [1]. Transitional cell carcinoma of the urothelium (TCCU) is of particular concern in Western countries, with the highest incidence rates in Europe and North America. In 2012, bladder cancer was the fifth most frequent malignancy with 4,772 deaths in France [2].

Recurrence of non-muscle-invasive urothelial carcinoma of the bladder is common despite treatment; low and high grade tumours have recurrence rates of $50 \%-70 \%$

\footnotetext{
*Correspondence: jacquesmedioni@gmail.com

This study was previously presented in part at the European Cancer

Congress (ESMO) in Amsterdam, September 10th, 2013.

${ }^{1}$ Medical Oncology Department, Hôpital Européen Georges Pompidou, 20, rue Leblanc, 75015 Paris, France

Full list of author information is available at the end of the article
}

and more than $80 \%$, respectively. Stage progression occurs in $15 \%-20 \%$ of non-muscle-invasive cases [3]. It is a muscle-invasive disease with poor progression and survival. Patients have a significantly high risk for progression to regional and systemic disease. Regardless of treatment, the 5-year overall survival (OS) rate for patients is approximately $50 \%$ [4]. For patients with metastatic disease, a cisplatin-based combination is the standard first-line treatment. However, approximately one patient out of two is not fit enough to receive cisplatin therapy and the alternative is usually a carboplatin-based regimen or a single agent. Median survival is approximately 14 months in cisplatin-eligible patients and less than 10 months for unfit patients. Although initial response rates are high in these patients, disease progression is common, creating a number of patients in need of effective second-line chemotherapy (CT) [5-7]. Until recently no standard of 
care was available for patients who failed a first systemic chemotherapy regimen. Studies exploring potential clinical activity of anticancer agents are mainly limited to non-randomized phase II trials without scientific evidence assessing a clinical benefit over supportive care [6, 7].

Vinflunine (VFL), a novel microtubule inhibiting agent, has been shown to be effective against a variety of solid tumour types including advanced TCCU. In vivo, VFL has shown to have a greater antitumor activity than other vinca alkaloids $[8,9]$. VFL is the first and only agent that has to date been assessed in a randomised phase III trial in a second-line setting, compared with best supportive care (BSC). In fact, prior to the development of this agent, there was neither an approved agent nor any established standard second-line therapy available in this setting. VFL plus BSC achieved a 2.6 month overall survival (OS) advantage in patients with advanced TCCU over BSC alone [10].

In Europe, VFL has been approved as a treatment option for patients with advanced urothelial cancer who failed a prior platinum-containing regimen [10-13]. VFL was introduced in France in September 2010 and has been integrated into the French and European guidelines $[6,7,14-16]$.

The first aim of the CURVE ("Carcinoma of the Urothelium: patients treated by VinfluninE") study was to retrospectively assess the efficacy and safety of VFL in second-line treatment for advanced or metastatic urothelial carcinoma in daily routine practice. The secondary objective was to confirm whether the prognostic factors for OS identified across the pivotal trials (performance status (PS), haemoglobin level and liver metastasis) were relevant or not in routine practice as well as to evaluate other possible prognostic factors for OS [17].

\section{Methods}

\section{Data source}

Eighty-eight French centres (i.e. private clinics, university hospitals, private hospitals) that had treated at least four patients with VFL for advanced or metastatic cancer after failure of platinum-based (CT) during 2011 (January-December) were contacted and 22 centres agreed to participate in the study. Prior written consent was not required from patients according to French regulations as this was an anonymous non-interventional study. Nevertheless, patients received complete information regarding the series and the anonymous collection of data for research. If a patient refused participation, the registration was not performed. Data were collected between December 2011 and March 2012.

\section{Ethics committee approval}

French Government approval, in compliance with the Helsinki Declaration, was received to use the patient data for the French multi-centre CURVE study from:
1- The Advisory Committee for the Treatment of Information - Ministry of Higher Education gave their approval on the $17^{\text {th }}$ September, 2012, Dossier $\mathrm{N}^{\circ}$ 12.526. 2- The National Commission of Informatics and Civil Liberty gave their approval on the $19^{\text {th }}$ October, 2012 Decision DR-2012-504, authorization demand $\mathrm{N}^{\circ} 912480$.

Characteristics of patients at the beginning of treatment therapy with VFL included age, performance status (PS), metastatic sites (i.e. liver, bone, lung, skin and brain), renal/liver function, relevant medical history i.e. gastro-intestinal chronic disease, cardiac disease, or previous treatment. The disease history was recorded, as well as, the number of previous treatment lines, regimen and duration of prior CT. VFL treatment modalities (starting dose, dose-escalation or reduction, number of cycles), the haematological and non-haematological adverse events were also recorded [18] including reasons for stopping treatment. Efficacy parameters i.e. response rate (radiologic assessment considering RECIST 1.1), progression-free survival and overall survival were included in the database.

\section{Patient inclusion criteria}

Only patients 18 or over, who had previously received a single-agent therapy with VFL for advanced or metastatic TCCU after progression to a platinum-based CT were enrolled in the study. Treatment with VFL was administered from $01 / 01 / 11$ to $31 / 12 / 11$.

\section{Assessment criteria efficacy}

Primary endpoint was OS, i.e. time between treatment start and date of last follow-up or death. Progressionfree survival was defined as the time between treatment start and disease progression (defined as the appearance of two or more lesions on a bone scan, or progression of visceral metastases by computer tomography scan according to RECIST 1.1.) or death. Efficacy was also measured using radiological response rate (complete response $[\mathrm{CR}]+$ partial $[\mathrm{PR}]$ response, and disease control $(\mathrm{CR}+\mathrm{PR}+$ Stable Disease [SD]) were based on the RECIST 1.1 criteria.

\section{Tolerance assessment}

The following adverse events were routinely recorded: neutropenia, febrile neutropenia, thrombocytopenia, anaemia, constipation, nausea/vomiting, infection, fever, asthenia/fatigue, neuropathy, stomatitis, mucositis, and abdominal pain. Other adverse events, based on a standard criteria were also recorded [18].

\section{Prognostic factors}

Several potential pre-treatment prognostic factors for OS were investigated in univariate/ multivariate analyses: PS (0 or $\geq 1)$, previous history of pelvic radiotherapy, 
haemoglobin level ( $\leq 10$ or $>10 \mathrm{~g} / \mathrm{dl}$ ), creatinine clearance ( $\leq 60$ or $>60 \mathrm{ml} / \mathrm{min}$ ), liver function (abnormal or normal), previous lines of CT ( $\leq 1$ or $>1)$, metastases at diagnosis, visceral metastases, liver metastases, lung metastases, previous treatment by cisplatin, previous treatment by cisplatin versus carboplatin, progression free interval before VFL $(<6$ or $\geq 6$ months), previous surgery (bladder or kidney/ureter).

\section{Statistical analysis and quality control}

Data were analysed (SAS system software version 9.3). Descriptive methods were used to present the data: quantitative variables were described either by mean plus standard deviation, or median with the range of values; qualitative variables were expressed by frequency and percentages, confidence interval of $95 \%$.

Survival data univariate analysis was performed using a log-rank test and multivariate analysis with a Cox proportional hazard model. Hazard ratios were estimated using the Cox proportional hazard model.
A scientific committee of the five authors controlled protocol conditions and reviewed all data prior to statistical analysis.

\section{Results}

\section{Data source}

Among the eighty-eight centres contacted twenty (i.e. $50 \%$ university hospital or cancer centres, $35 \%$ private clinics and $15 \%$ private hospitals) agreed to participate in the study with data collected from 134 patients.

\section{Previous medical history of patients}

In the intention to treat (ITT) population the sex ratio (female/male) was 11.2/88.8, median age 65.3 [range 42.1-88.2] with patients $\geq 65$ years and $\geq 75$ years old representing $52 \%$ and $21 \%$, respectively. PS was 0 in 34 patients ( $25 \%), 1$ in 62 (46\%) and PS $\geq 2$ in 31 (23\%); information was missing for 7 patients. (Main Patients Characteristics see: Table 1.)

All patients received prior chemotherapy, with the majority $(95.5 \%)$ for advanced or metastatic disease.

Table 1 Patients characteristics and potential prognostic factors

\begin{tabular}{|c|c|}
\hline ITT population & $N=134$ \\
\hline Gender (\%) F/ M & $15(11.2) / 119(88.8)$ \\
\hline Median Age (years, min/max) & $65.3[42.1-88.2]$ \\
\hline$[35-50[N(\%)$ & $7(5.2)$ \\
\hline [50-65 [N (\%) & $57(42.5)$ \\
\hline$[65-75[N(\%)$ & $42(31.3)$ \\
\hline$\geq 75 \mathrm{~N}(\%)$ & $28(20.8)$ \\
\hline \multicolumn{2}{|l|}{ Performance Status N (\%) } \\
\hline $0 / 1 / \geq 2 / \mathrm{Na}$ & $34(25.4) / 62(46.3) / 31(23.1) / 7(5.2)$ \\
\hline \multicolumn{2}{|l|}{ Metastases N (\%) } \\
\hline Lung/Liver/Bone/Lung + Liver/Other & $52(38.8) / 38(28.4) / 32(23.9) / 76(56.7) / 20(14.9$ \\
\hline \multicolumn{2}{|l|}{ Creatinine Clearance N (\%) } \\
\hline$>60 \mathrm{ml} / \mathrm{mn} /[40-60] \mathrm{ml} / \mathrm{mn} /<40 \mathrm{ml} / \mathrm{mn} / \mathrm{Na}$ & $67(50.0) / 51(38.1) / 13(9.7) / 3(2.2)$ \\
\hline \multicolumn{2}{|l|}{ Haemoglobin N (\%) } \\
\hline$<=10(\mathrm{~g} / \mathrm{dl}) />10(\mathrm{~g} / \mathrm{dl}) / \mathrm{Na}$ & $32(23.9) / 100(74.6) / 2(1.5)$ \\
\hline \multicolumn{2}{|l|}{ Liver Function N (\%) } \\
\hline Normal/Abnormal/Na & $114(85.1) / 13(9.7) / 2(1.5)$ \\
\hline \multicolumn{2}{|l|}{ Chronic Constipation N (\%) } \\
\hline $\mathrm{No} / \mathrm{Yes} / \mathrm{Na}$ & $127(94.8) / 6(4.5) / 1(0.7)$ \\
\hline Prior Radiotherapy N (\%) & $28(20.9)$ \\
\hline Progression within 6 months after prior CT N (\%) & $112(83.6)$ \\
\hline Number of Advanced or Metastatic CT at Baseline [N, (\%)] Total pts & $128(95.5)$ \\
\hline $1 \mathrm{CT}$ lines & $93(69.4)$ \\
\hline 2 CT lines & $31(23.1)$ \\
\hline $3 \mathrm{CT}$ lines & $4(3)$ \\
\hline Patients with perioperative $C T$ alone at Baseline $[\mathrm{N},(\%)]$ & $5(3.7 \%)$ \\
\hline
\end{tabular}


Twenty-six percent $(n=35)$ of patients received $\geq 2$ prior chemotherapy lines for an advanced/metastatic urological cancer and 6 patients (4.5\%) received only one prior chemotherapy regimen as perioperative treatment in the neoadjuvant (1 patient) or adjuvant setting (5 patients).

All but one patient received a prior platinum salt: a cisplatin-based regimen was administered in $69.4 \%$ of patients and $50.7 \%$ received a carboplatin-based chemotherapy, considering that some patients received several prior CT lines (Table 1).

Progression within 3 months and 6 months after prior CT was observed in $54 \%$ and $82 \%$ of patients, respectively. Prior local therapies in the ITT population were: 28 patients $(20.9 \%)$ had undergone prior radiotherapy (RT), 19 for bladder cancer; 112 patients (83.6\%) had undergone prior surgery, mainly localized to the bladder alone (76 patients), or $22.4 \%$ for the upper urinary tract.

\section{Vinflunine treatment modalities}

The median number of cycles was $5[1 ; 23]$ with a median duration of treatment by VFL of 3.1 months [0.03; 15.2]. Patients started i.v. VFL at either 320, 280, 250 or < $250 \mathrm{mg} / \mathrm{m}^{2}$ dose for a $20 \mathrm{~min}$ infusion, 3 weekly-based. VFL starting dose was $\geq 280 \mathrm{mg} / \mathrm{m}^{2}$ in $81 \%(n=108)$ of patients with a median initial dose of $280 \mathrm{mg} / \mathrm{m}^{2}$ (min: $120 \mathrm{mg} / \mathrm{m}^{2}$; $\max : 320 \mathrm{mg} / \mathrm{m}^{2}$ ). In fact, $54.5 \%$ of patients initially received $280 \mathrm{mg} / \mathrm{m}^{2}$ and $26.1 \%$ received $320 \mathrm{mg} / \mathrm{m}^{2}$. The relative dose intensity reached the median value of $92.7 \%(18.8-125.7)$. At least one dose reduction occurred in $16 \%$ of patients.

In terms of treatment duration, $17.9 \%$ of patients had a completion of cycles initially scheduled. Treatment was stopped for toxicity in only $6 \%$ of patients but primarily stopped for disease progression or death (63.5\%).

\section{Tolerance and safety}

In patients, most frequent grade III-IV toxicities (whatever the drug relationship) were asthenia and fatigue (21 \%, $n=28)$, neutropenia (17 \%, $n=23)$, anaemia (8 \%, $n=11)$, constipation ( $8, n=11)$ and abdominal pain ( $5 \%, n=7)$. Other grade III and IV toxicities were observed with a frequency below $5 \%$ of patients. Occlusion occurred in one patient with no toxic deaths. Prophylaxis against vomiting and constipation were prescribed in $92 \%$ and $86 \%$ of patients respectively. Table 2 shows the reported adverse events (all grades and grade III-IV).

\section{Primary end point - OS}

After a median follow-up of 17.6 months [95 \% CI 15.3 - 18.8] the median OS for the entire population was 8.2 months [95 \% CI 6.5 - 9.4] (Fig. 1). Among the 31 patients with $\mathrm{PS} \geq 2$ at treatment initiation, median OS was 3.3 [95 \% CI 1.9-5.6].
Table 2 Most common adverse events (regardless of the drug-relationship)

\begin{tabular}{lll}
\hline Adverse event & All grades N (\%) & Grades 3/4 N (\%) \\
\hline Anaemia & Haematology & \\
Leucopenia & $60(44.8)$ & $11(8.2)$ \\
Neutropenia & $23(17.2)$ & $7(5.2)$ \\
Thrombocytopenia & $34(25.4)$ & $23(17.2)$ \\
Febrile Neutropenia & $14(10.4)$ & $4(3)$ \\
& $5(3.7)$ & $4(3)$ \\
Asthenia, Fatigue & NON HAEMATOLOGY & \\
Constipation & $74(55.2)$ & $28(20.9)$ \\
Abdominal pain & $55(41.0)$ & $11(8.2)$ \\
Subocclusive syndrome & $21(15.7)$ & $7(3)$ \\
Neuropathy & $5(3.7)$ & $3(2.1)$ \\
Toxic death & $10(7.5)$ & $1(0.7)$ \\
\hline
\end{tabular}

Following VFL, 62 patients (46\%) received further treatment, from 1 (46 patients) to 3 additional lines, mainly CT (59 patients).

\section{Secondary efficacy criteria}

Median PFS was 4.2 months [2.8-4.8] (Fig. 2). The RR was $22 \%$ with $5 \%$ and $17 \%$ of complete and partial responses, respectively (Table 3 ). The disease control rate was $51 \%$ with a median duration of 7.7 months [6.0-9.4].

\section{Independent prognostic factors for OS}

Based on univariate analysis at baseline, four factors were significantly associated with OS: PS ( 0 versus $\geq 1$ ), baseline haemoglobin level ( $>10$ versus $\leq 10 \mathrm{~g} / \mathrm{dl}$ ), liver function (normal versus abnormal) and liver metastasis (yes versus no). For PS values 0 or $\geq 1$, OS was $14.5 / 6.1$, $p=0.0002$ hazard ratio (HR) 0.40 ; for baseline haemoglobin $>10 \mathrm{~g} / \mathrm{dL}$ or $\leq 10 \mathrm{~g} / \mathrm{dL}$, OS 9.6/2.4 months, $p<.0001$, HR 0.30; presence of baseline liver metastasis (yes or no), OS was 9.4/5.6 months, $p=0.0059$ (HR) 0.55; and according to the normality or abnormality of liver function, OS was $8.7 / 1.6$ months, $p=0.0001$ (HR) 0.31 .

All factors except liver function in the multivariate analysis had a statistically significant effect on OS and none of the other parameters were significantly correlated with OS.

\section{Distribution of patients according to risk groups}

According to previously published models, median OS was assessed based on the presence of zero, one, two or three risk factors (PS $\geq 1$, haemoglobin $\leq 10 \mathrm{~g} / \mathrm{dl}$ and liver metastasis); these results are shown in Table 4 with $21.6 \%$ of the 134 patients in risk group $0,37.3 \%$ in risk 


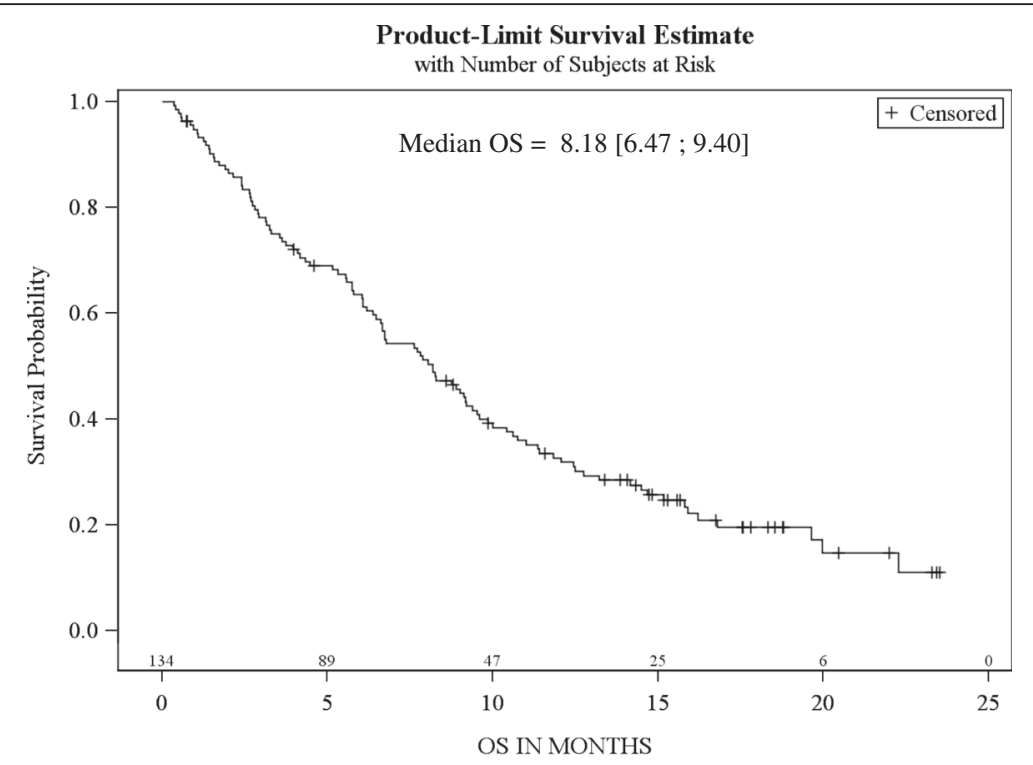

Fig. 1 Overall Survival (ITT, $n=134)$

group 1, 25.4 \% in risk group 2, $9.7 \%$ in risk group 3 and for $6 \%$ of patients information not available (Fig. 3)

\section{Discussion}

To date, the CURVE study represents the largest cohort of patients following cytotoxic treatment after failure of a prior platinum-based CT regimen in urothelial carcinoma.

The aims were not only to report on patients treated with vinflunine in routine daily practice, but also conditions of vinflunine administration as well as provide data on efficacy and toxicity. The analysis based on real life conditions of possible prognostic factors of OS is useful when compared to previously published data from clinical trials [17].

This survey reflects the current second-line management of metastatic UC in France with some patients exhibiting worse conditions (age and PS) that are often reported in current practice or clinical trials. In fact, the median age was 64.2 years in the pivotal phase III study, and only patients with PS 0 and 1 were enrolled the phase II and III trials in contrast to $23 \%$ of PS 2 reported in our study [10-12].

The obvious limitation of this study is that it was retrospective. Moreover, not all the data concerning the

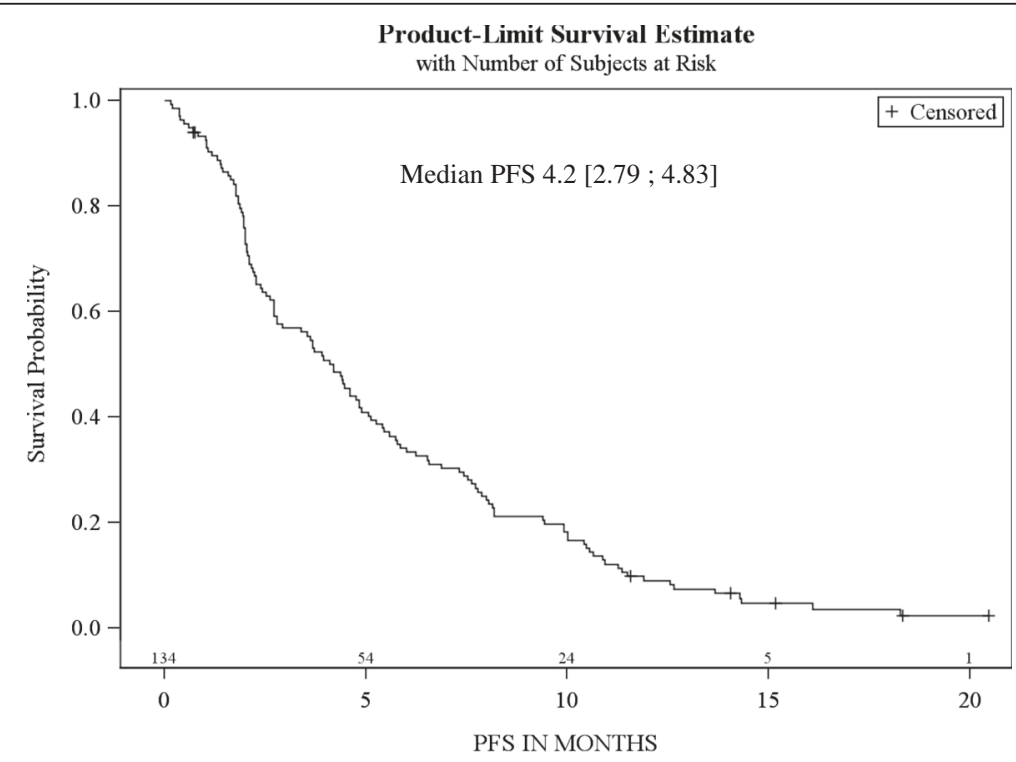

Fig. 2 Progression-free Survival (ITT, $n=134)$ 
Table 3 Efficacy results

\begin{tabular}{ll}
\hline ITT population & $N=134$ \\
\hline Best Overall Response & \\
Complete Response $(\mathrm{n}, \%)$ & $7(5.2 \%)$ \\
Partial Response $(\mathrm{n}, \%)$ & $23(17.2 \%)$ \\
Stable Disease $(\mathrm{n}, \%)$ & $38(28.4 \%)$ \\
Response Rate (CR + PR) (\%, range) & $30(22.4 \%)$ \\
Disease Control (CR + PR + SD) (\%, range) & $68(50.7 \%)$ \\
Median duration of response (month, range) & $4.9[3.2-6.5]$ \\
Median duration of stabilization (month, range) & $7.8[5.7-9.4]$ \\
\hline
\end{tabular}

patients treated in France with vinflunine during the year 2011 are reported in this study. Nevertheless, the protocol followed a strictly predefined methodology under the supervision of the scientific committee, all centres with a major recruitment of bladder cancer were contacted, and all those that participated had treated at least 4 patients, which reflects their experience in treating VFL patients. The series were considered to be exhaustive in each participating centre and no discrepancy was observed when the pre-study estimated number of cases was compared to the registered patients. No patient selection bias for VFL related outcomes was detected during the quality control assessment.

Regarding treatment modalities in daily practice, $81 \%$ of patients were treated with VFL starting doses of 280 or $320 \mathrm{mg} / \mathrm{m}^{2}$ as per SmPC as recommended by the official guidelines. There was in fact a high median number of cycles, i.e. 5 cycles as compared to 3 in the phase III study. One patient received up to 25 cycles. This information on treatment duration is reassuring regarding VFL tolerance under routine conditions.

Toxicity was manageable: i.e. main grade 3 or 4 toxicities were neutropenia $17 \%$, anaemia $8 \%$, asthenia/fatigue $21 \%$ and constipation $8 \%$ with no toxic deaths.

Two similar European studies reporting VFL efficacy and safety in routine practice were recently reported. In a prospective non-interventional study, 77 unselected patients (within the VFL market authorization conditions

Table 4 Distribution of patients according to risk groups

\begin{tabular}{lll}
\hline$P<0.0001 \mathrm{HR} 1.98$ & $N=134$ & OS Median months [95 \% Cl] \\
\hline Risk 0 & 29 & $13.2[9.6-\mathrm{NR}]$ \\
Risk 1 & 50 & $9.9[6.7-11.8]$ \\
Risk 2 & 34 & $3.5[2.7-6.5]$ \\
Risk 3 & 13 & $2.4[1.1-6.17]$ \\
Missing $^{a}$ & 8 &
\end{tabular}

Patients group Risk 0, 1, 2 or 3: patients having $0,1,2$ or 3 adverse factor respectively

Prognostic factors: PS $\geq 1$, haemoglobin $\leq 10 \mathrm{~g} / \mathrm{dl}$, presence of liver metastasis at baseline

${ }^{a}$ Patients with at least one missing prognostic factor of PS 0-1) with advanced or metastatic urothelial carcinoma were treated in Germany [19]. The mean number of administered cycles of VFL was 4.7 and $34 \%$ of patients received the 6 planned cycles. Most frequent grade 3 or higher haematological toxicities were leucopenia (17\%) and anaemia (6.5\%). As regards prophylaxis against nausea/vomiting or against constipation, grade 3 or higher non-haematological toxicities were constipation (5 \%) and nausea/vomiting (5\%). Median OS time was 7.7 months and disease control rate was $53 \%$. These prospective results are similar to those in the retrospective CURVE study.

Results from another ongoing Spanish study were also presented in 2013. Chirivella et al. reported their initial results based on 66 patients with only 5 PS 2. Median duration of treatment was also 5 cycles $[1,17,20]$ with some long lasting treatments. Grade 3 or higher toxicities were: $9 \%$ neutropenia, $6 \%$ constipation and abdominal pain, $6 \%$ nausea or vomiting with an OS of 10.6 months. These toxicity and efficacy results are quite similar to the CURVE study. The Spanish population was mostly elderly (median age 67 years) but with better performance status (only 7 \% PS2). The difference in PS could possibly explain the more favourable OS in the Spanish cohort while other efficacy outcomes and toxicity were similar.

In the phase III controlled randomised clinical trial reported by Bellmunt et al. in 2009 updated in 2013, after a median follow-up of 45.4 months, median OS was $6.9 \mathrm{~m}$ and $4.3 \mathrm{~m}$ for VFL plus BSC versus BSC alone, respectively in the modified ITT population. [21]. The median age was lower than in the CURVE study for the VFL treated group (64.2 years) and PS was restricted to PS 0 or 1. Similarly to the CURVE study, progression or relapse within 6 months following prior CT accounted for $83 \%$ of patient cases and liver metastasis were present in $29 \%$. In contrast, a baseline haemoglobin below $10 \mathrm{~g} / \mathrm{dL}$ was reported at a higher rate ( $86 \%$ of patients) in the phase III study which probably represents, apart from an initial more restricted patient selection (including PS and only one prior chemotherapy line), the main difference between the populations' characteristics.

In the Bellmunt et al. 2009 study, the main grade 3 or 4 toxicities for VFL + BSC were neutropenia (50\%), anaemia (19\%), fatigue (19\%), constipation (16\%), and febrile neutropenia (6\%) [10].

The toxicity was less pronounced in our daily experience than in the pivotal trial. This was a reproducible observation across the other studies performed in routine practice, either prospective or retrospective, and could be linked to the high rate of constipation prevention with laxatives and dietary measures at each cycle of VFL administration. In our study, $63 \%$ of patients received a prophylaxis with G-CSFs thus preventing neutropenia. 


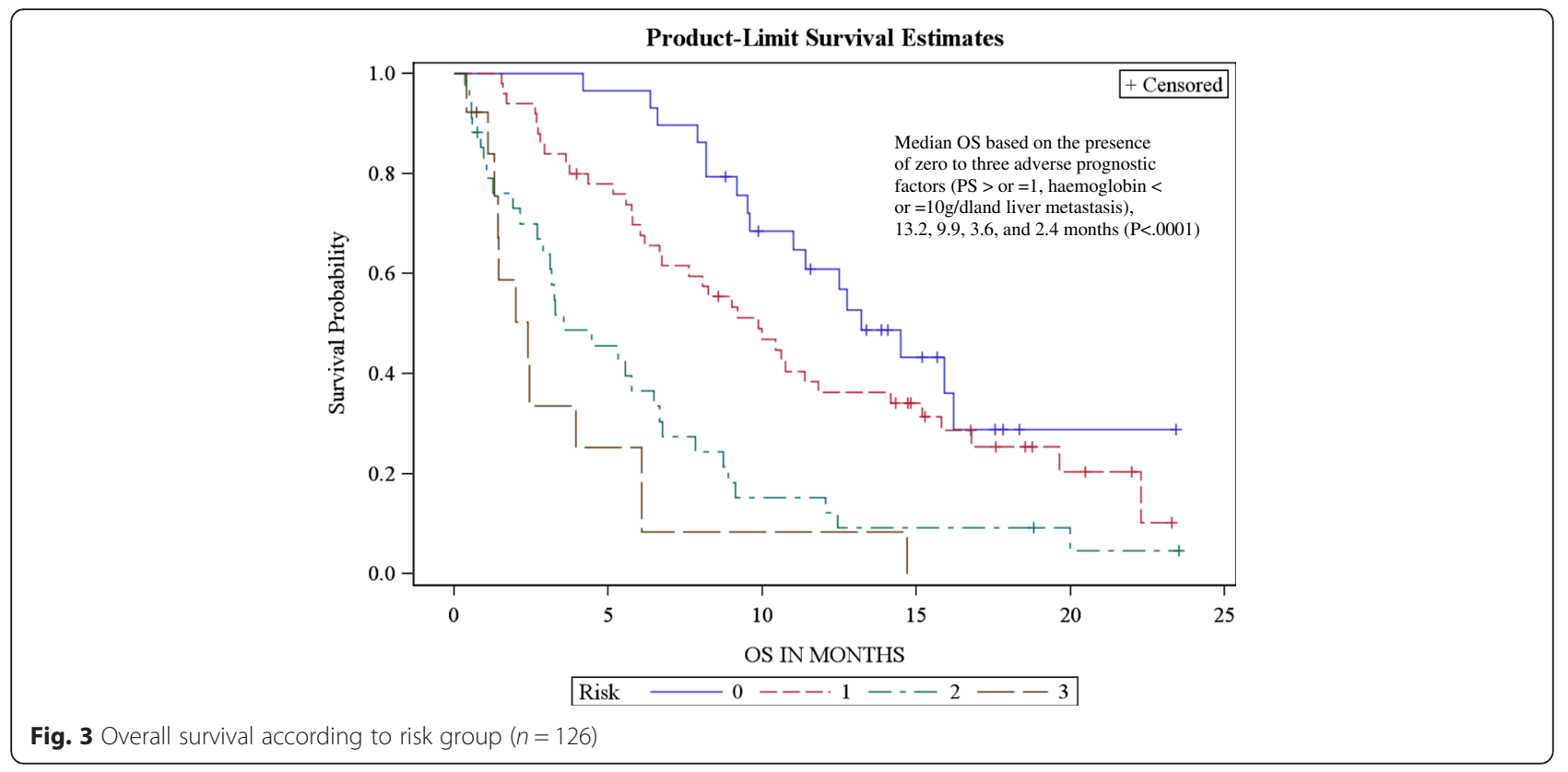

The current analysis of prognostic factors for OS is consistent with the data published from the pivotal study. Bellmunt et al. showed that PS, haemoglobin, liver metastasis, were prognostic factors of overall survival, but also liver enzymes AST and alkaline phosphatases had a lesser relationship to OS. In the same phase III clinical trial, based on multivariate analysis, the internal validation identified PS of more than 0 , a haemoglobin level less than $10 \mathrm{~g} / \mathrm{dL}$, and the presence of liver metastasis as the main adverse prognostic factors for OS. External validation confirmed these prognostic factors. We also assessed OS in the four subgroups of the published model based on the presence of zero, one, two or three similar prognostic factors with the median OS times of 13.2, 9.9, 3.6, and 2.4 months $(P<.0001)$, respectively. The current analysis is consistent with the phase III findings where median OS was 14.2, 7.3, 3.8 and 1.7 months, respectively. This is roughly comparable even if the presence of PS 2 patients in the CURVE study may have played a role in the later risk groups [17].

Our study further confirms the value of PS, haemoglobin level and liver involvement as useful prognostic factors for OS. In fact, both the presence of liver metastasis and liver dysfunction were significantly correlated with OS in the univariate analysis. The effects of haemoglobin level and liver involvement was confirmed in the multivariate analysis although the presence of liver metastasis and liver function are not clinically independent parameters. The group of patients with 0 or 1 prognostic factors had the longest OS in our series and probably benefited the most by vinflunine treatment. Therefore, patients should be treated at an early stage after platin relapse, to avoid anaemia and alteration in performance status.
Yafi et al., in 2011, reported that no standard therapy had been established for patients who recur or are refractory to first-line therapy and that second-line VFL treatment, by way of superiority over best supportive care, has shown promise in a phase III trial [22]. The positive treatment effect of VFL on survival shown in the first publication of the phase III pivotal trial was recently confirmed in a recent up-dated report including a long term analysis. The results are consistent over time and confirm that VFL is a valuable option in patients with advanced TCCU after failure of platinum-based regimens. In addition, some long term survivors treated with vinflunine were observed for as long as 40 months follow-up (none in the BSC group). This is consistent with the long lasting treatments that were reported in routine practice [21].

Finally, several other clinical trials with VFL in bladder cancers are ongoing, notably regarding first line treatment for patients unfit for cisplatin-based chemotherapy. An international study (JASINT1) should provide data comparing vinflunine in association with gemcitabine as well as vinflunine with carboplatin [23]. In 2014 a study of 102 patients, by Castellano et al. in Spain, evaluated the safety and effectiveness of VFL in patents with TCCU after failure of one platinum-based systemic therapy in clinical practice with similar results to our study [24]. In their series they reported that $65.7 \%$ of patients demonstrated a clinical benefit with VFL and an OS for all patients of 10 months (range 7.3-12.8). Recently, in agreement with our results, Retz et al. concluded: "A systematic gastrointestinal prophylaxis is strongly recommended to achieve a good safety profile. The vinflunine starting dose of $320 \mathrm{mg} / \mathrm{m}^{2}$ was most efficacious 
with a median OS of 10.4 months and should therefore be considered in all eligible patients [25]. This study adds further support to the EAU recommendation for the use of vinflunine as second-line therapy in advanced UCC after failure of platinum-based treatment".

\section{Conclusion}

The CURVE study was a major retrospective study in an unselected population of patients with pre-treated advanced or metastatic urothelial carcinoma. VFL efficacy as previously reported in the phase III pivotal study was confirmed or surpassed considering all criteria in real life patients. The drug was safe, as all the gastrointestinal prophylactic recommendations were widely followed. Also the study was able to provide efficacy data for performance status 2 patients. Prognostic factors for OS in routine practice (performance status, haemoglobin, liver metastasis) were similar as those previously reported after the phase III trial. Risk group of patients with 2 or 3 adverse prognostic factors had a short median survival time but the presence of PS2 patients may have impacted the findings. In patients with or without one adverse prognostic factor, the median survival time ranged from 10 to 13 months.

\section{Competing interests}

The authors declare that they have no competing interests.

\section{Authors' contributions}

JM conceived the study and participated in its design, coordination and helped to draft the manuscript. MDP participated in the design of the study and performed the statistical analysis. AG participated in the statistical analysis. MDP performed the data acquisition and analysis. $\mathrm{CT}$ performed the quality control of data. DS performed manuscript editing and review. All authors have read and approved the final manuscript.

\section{Key message}

This study accurately reflects the routine management of metastatic urothelial carcinoma in France. Vinflunine efficacy has been confirmed in unselected patients, and the drug is safe provided that there is gastrointestinal and haematological prophylaxis. The analysis of prognostic factors for overall survival is consistent with pivotal trials. Survival in performance status 2 patients is limited. To date, the CURVE (urothelial carcinoma patients treated by vinflunine in French) study represents the largest cohort of patients that were assessed following cytotoxic treatment after failure of a prior platinum-based CT regimen in urothelial carcinoma.

\section{Acknowledgement}

\section{Funding}

This study was supported by Pierre Fabre Laboratories - France.

\section{Disclosure}

In 2012 Drs. J. Médioni, M. Di Palma, A. Guillot, D. Spaeth, C. Théodore all received a fee from Pierre Fabre Laboratories - France for their participation as members of the CURVE study Scientific Committee.

The authors are grateful to Richard Medeiros - Medical Editor, Medical

Editing International for editing various versions of the manuscript.

\section{Author details}

${ }^{1}$ Medical Oncology Department, Hôpital Européen Georges Pompidou, 20, rue Leblanc, 75015 Paris, France. ${ }^{2}$ Department of Medicine, Gustave Roussy Institute, 114 Rue Édouard Vaillant, 94805 Villejuif, France. ${ }^{3}$ Lucien Neuwirth Institute of Cancerology, 108 B Avenue Albert Raimond, 42270
Saint-Priest-en-Jarez, France. ${ }^{4}$ Gentilly Oncology Centre, 2 rue Marie Marvingt, 54100 Nancy, France. ${ }^{5}$ Department of Oncology, Hôpital Foch, 92151 Suresnes, France.

Received: 9 March 2015 Accepted: 9 March 2016

Published online: 14 March 2016

\section{References}

1. Ferlay J, Soerjomataram I, Ervik M, Dikshit R, Eser S, Mathers C, Rebelo M, Parkin DM, Forman D, Bray, F. GLOBOCAN 2012 v1.0, Cancer Incidence and Mortality Worldwide: IARC CancerBase No. 11 [Internet]. Lyon, France: International Agency for Research on Cancer; 2013. Available from: http:// globocan.iarc.fr, accessed on day/month/year.

2. French National Cancer Institute (Institut National du Cancer) Epidemiology of cancer in France - Incidence and mortality. http://www.ecancer.fr/ content/download/142167/1769928/file/Les\%20cancers\%20 en\%20france\%20-\%20Edition\%202015\%20-\%20Faits\%20et\%20chiffres.pdf

3. Prasad SM, Decastro GJ, Steinberg GD. Urothelial carcinoma of the bladder: definition, treatment and future efforts. Nat Rev Urol. 2011:8:631-42. doi:10. 1038/nrurol.2011.144Review.

4. Sverrisson FE, Espiritu PN, Spiess P. New therapeutic targets in the management of urothelial carcinoma of the bladder. Res Rep Urol. 2013;5: 53-65. 10.2147/RRU.S29131.

5. Nadal R, Bellmunt J. New treatments for bladder cancer: when will we make progress? Curr Treat Options Oncol. 2014;15(1):99-114.

6. Bellmunt J, Orsola A, Wiegel T, Guix M, De Santis M, Kataja V, et al. Bladder cancer: ESMO Clinical Practice Guidelines for diagnosis, treatment and follow-up. Ann Oncol. 2011;22 Suppl 6:vi45-9.

7. Stenzl A, Witjes JA, Compérat E, Cowan N.C, De Santis M, Gakis G, Lebret T, Ribal M J, Sherif A. EAU Guidelines on Bladder Cancer Muscle-invasive and Metastatic. European Association of Urology 2012 update.www.uroweb.org.

8. Ngan VK, Bellman K, Panda D, Hill BT, Jordan MA, Wilson L. Novel actions of the antitumor drugs vinflunine and vinorelbine on microtubules. Cancer Res. 2000;18:5045-51.

9. Gerullis H. Vinflunine: a fluorinated vinca alkaloid for bladder cancer therapy. Drugs of Today. 2011;47:17-25.

10. Bellmunt J, Théodore C, Demkov T, Komyakov B, Sengelov L, Daugaard G, Caty A, Carles J, Jagiello-Gruszfeld A, Karyakin O, Delgado FM, Hurteloup P, Winquist E, Morsli N, Salhi Y, Culine S, von der Maase H. Phase III trial of vinflunine plus best supportive care compared with best supportive care alone after a platinum containing regimen in patients with advanced transitional cell carcinoma of the urothelial tract. J Clin Oncol. 2009;27:4454-61.

11. Culine S, Theodore C, De Santis M, Bui B, Demkow T, Lorenz J, Rolland F, Delgado FM, Longerey B, James N. A Phase II study of vinflunine in bladder cancer patients progressing after first-line platinum-containing regimen. $\mathrm{Br}$ J Cancer. 2006;94:1395-401.

12. Vaughn DJ, Srinivas S, Stadler WM, Pili R, Petrylak D, Sternberg CN, Smith DC, Ringuette S, de Wit E, Pautret V, George C. Vinflunine in platinumpretreated patients with locally advanced or metastatic urothelial carcinoma: results of a large Phase 2 study. Cancer. 2009;115:4110-7.

13. CHMP Assessment Report for JAVLOR ${ }^{\oplus}$ - International non-proprietary name Javlor ${ }^{\circledast}$ European Public Assessment Report doc EMEA/CHMP/370293/2009.

14. Witjes J A, Compérat E, Cowan NC, De Santis M, Gakis G, Lebret T, Ribal MJ, Sherif A. Guidelines on Muscle-invasive and Metastatic Bladder Cancer update March 2013.

15. Soulié M, Coloby P, Irani JT, Lebret JJ, Patard C, Pfister P, Richaud J, Rigaud L, Salomon, and Members of CCAFU. CCAFU Recommendations 2013: Diagnosis, treatment, follow-up of urological cancers. Prog Urol. 2010;20 Suppl 4:S211-4.

16. Pfister $C$, Roupret $M$, Neuzillet $Y$, Larré $S$, Pignot $G$, Quintens $H$, Houedé $N$, Compérat E, Colin P, Roy C., Davin J L, Guy L, Irani J, Lebret T, Coloby P, Soulié M, and Members of CCAFU. Recommendations 2013: Bladder carcinoma. Prog Urol. 2013;23 Suppl 2:S105-25.

17. Bellmunt J, Choueiri TK, Fougeray R, Schutz FAB, Salhi $Y$, Winquist E, Culine $\mathrm{S}$, von der Maase $H$, Vaughn D J, Rosenberg, J E. Prognostic factors in patients with advanced transitional cell carcinoma of the urothelial tract experiencing treatment failure with platinum-containing regimens. J Clin Oncol. 2010;28:1850-5.

18. Common Terminology Criteria for Adverse Events (CTCAE) v3.0 (Publish Date August 9, 2006) http://ctep.cancer.gov/protocolDevelopment/ electronic_applications/ctc.htm 
19. Hegele A, de Geeter P, Goebell P, Matz U, de Schultz W, Retz M. Vinflunine in routine practice for the treatment of advanced or metastatic urothelial cell carcinoma in Germany. Eur J Cancer. 2013;49(Suppl2):S669.

20. Chirivella I, Grande E, Lopez-Criado P, González GB, Fernández O, Santander C. Vinflunine as a second-line chemotherapy for patients with transitional cell carcinoma of the urothelium: a multicentre retrospective study. Eur J Cancer. 2013;49 Suppl 2:S671.

21. Bellmunt J, Fougeray R, Rosenberg JE, von der Maase H, Schutz FA, Salhi Y, et al. Long-term survival results of a randomized phase III trial of vinflunine plus best supportive care versus best supportive care alone in advanced urothelial carcinoma patients after failure of platinum-based chemotherapy. Ann Oncol. 2013;24:1466-72.

22. Yafi FA, North S, Kassouf W. First- and second-line therapy for metastatic urothelial carcinoma of the bladder. Curr Oncol. 2011;18:e25-34.

23. De Santis M, Wiechno P, Lucas C, Su WC, Albige SL, Lin CC, Vaissière N, Burillon J.P, Culine S. Preliminary data on feasibility of vinflunine (VFL)-based combinations as 1st line in CDDP-unfit patients (pts) with advanced urothelial carcinoma (UC): VFL/gemcitabine vs. VFL/CBDCA in a randomised international phase II trial (JASINT1). Eur J Cancer. 2013;49(Suppl2):S642.

24. Castellano D, Puente J, de Valasco G, Chirivella I, López-Criado P, Mohedano $\mathrm{N}$, et al. Safety and effectiveness of vinflunine in patients with metastatic transitional cell carcinoma of the urothelial tract after failure of one platinum-based systemic therapy in clinical practice. BMC Cancer. 2014;14:779.

25. Retz M, de Geeter P, Goebell PJ, Ullrich Matz U, de Schultz W, Hegele A. Vinflunine in routine clinical practice for the treatment of advanced or metastatic urothelial cell carcinoma - data from a prospective, multicenter experience. BMC Cancer. 2015;15:455. doi:10.1186/s12885-015-1434-3.

\section{Submit your next manuscript to BioMed Central and we will help you at every step:}

- We accept pre-submission inquiries

- Our selector tool helps you to find the most relevant journal

- We provide round the clock customer support

- Convenient online submission

- Thorough peer review

- Inclusion in PubMed and all major indexing services

- Maximum visibility for your research

Submit your manuscript at www.biomedcentral.com/submit

) Biomed Central 